\title{
Los acuerdos de maternidad subrogada: nuevos retos en la protección de los derechos de la mujer y la infancia
}

Surrogacy Motherhood Agreements: new challenges in the protection of the rights of women and children

Acordos sobre Maternidade Subrogada: novos desafios na proteção dos direitos da mulher e da infância

Maria Olga Sánchez Martínez ${ }^{1}$

RESUMEN. Los avances en materia de reproducción humana asistida, junto a la relativización de las fronteras, suponen un reto continuo para la ciencia, la ética y el derecho. Un ejemplo de tal situación es la maternidad subrogada, cuya prohibición en algunos países no impide que recurran a ella ciudadanos afectados por tal prohibición en otros Estados cuya práctica está permitida. Tampoco impide que se pretenda el reconocimiento de efectos jurídicos sobre los bebes nacidos sobre aquellos acuerdos. Junto a cuestiones de salud, la protección de los derechos de mujeres y niños, se erigen en los argumentos de referencia que sustentan la nulidad de los acuerdos de gestación subrogada, siendo paradójico que esos mismos argumentos se conviertan en el cauce que va abriendo paso al reconocimiento de efectos jurídicos.

Palabras llave: Maternidad subrogada. Derechos de la mujer. Derechos de los niños.

ABSTRACT: Advances in assisted human reproduction, by the relativization of borders, pose a continuing challenge to science, ethics and law. An example of such a situation is surrogacy, which ban in some countries does not preclude having recourse to citizens affected by such a ban in other States whose practice is permitted. It does not prevent the recognition of legal effects on babies born to those agreements were intended. Along with issues of health, protection of the rights of women and children are erected in reference arguments that support the nullity of surrogacy agreements, being paradoxical that the same arguments become the channel that is making its way to recognition of legal

effects.

Keywords: Surrogate motherhood. Women's rights. Children's right.

RESUMO: Os avanços na reprodução humana assistida, pela relativização das fronteiras, constituem um desafio contínuo até a ciência, ética e direito. Um exemplo de tal situação é sub-rogação, que proíbem, em alguns países não exclui recorrer aos cidadãos afectados por essa proibição, em outros Estados cuja prática é permitida. Não impede o reconhecimento de efeitos jurídicos sobre os bebês nascidos de tais acordos se destinavam. Juntamente com as questões de saúde, a protecção dos direitos das mulheres e crianças, são erguidas em argumentos de referência que suportam a nulidade dos acordos de sub-rogação, sendo paradoxal que os mesmos argumentos se tornar o canal que está a fazer o seu caminho para reconhecimento de efeitos jurídicos.

\footnotetext{
${ }^{1}$ Profesora Titular de Filosofía del Derecho. Facultad de Derecho, Universidad de Cantabria. España. Email: maria.sanchez@unican.es
} 
Palavras-chave: Barriga de aluguel. Direitos das Mulheres. Direitos das Crianças

\section{Introducción}

\section{La familia y la pérdida progresiva de sus elementos naturales}

Si hay algo común en todo el mundo, y en todas las épocas, es el reconocimiento de la importancia de la familia y las funciones que desempeña en la sociedad. La familia es un sistema social universal, un elemento clave en las estrategias de reproducción, no sólo biológica, sino económica, social y cultural y un elemento imprescindible en la formación de nuevos ciudadanos (1), (2). Satisface necesidades que no pueden ser suplidas por ninguna otra institución, pero también es generadora de necesidades que reclaman la intervención de otras instituciones, con el objetivo de que se satisfagan los derechos de los integrantes de la familia y, especialmente, de quienes se encuentran en una posición más vulnerable dentro de la misma.

Si bien la familia es un fenómeno universal, no hay un modelo universal de familia. La familia es un fenómeno histórico y su historia es la de un cambio constante, al mismo tiempo que lo hace la sociedad en que se inserta. La lógica consecuencia de que la familia sea una realidad social y cultural de enorme vitalidad es la diversidad familiar. En este proceso de cambio continuo, aún no podemos hablar de nuevos modelos familiares concluidos. Butler señala que las formas familiares son "formas sociales viables" que pueden ser "útilmente desafiadas"(3). Siendo así, la familia "venidera" probablemente tendrá que "reinventarse" una vez más (4).

Diversas transformaciones económicas, políticas, sociales, religiosas, morales, tecnológicas y culturales han contribuido a modificar el desenvolvimiento de las familias y a pluralizar unos modelos de familias cada vez más complejos. Un tratamiento especial requieren en este momento los cambios generados por los avances tecnológicos en materia biológica y médica, de un mundo globalizado que relativiza las fronteras y su incidencia en uno de los mayores desafíos a los que se han enfrentado las familias en los últimos tiempos: la pérdida progresiva de los elementos naturales en su origen. 
En el orden simbólico familiar la vinculación de la familia a la naturaleza es tan potente que los cambios en este sentido son acompañados de grandes incertidumbres y temores, en los que no están ausente los agoreros que proclaman el fin de la familia y hasta de la propia civilización. El binomio sexualidad/procreación que da origen a la familia natural es la base de una construcción social, cultural y jurídica de un modelo familiar concreto: la llamada familia tradicional, que es matrimonial, indisoluble y de diferenciación sexual. La disolución del matrimonio y la protección de los hijos, iguales ante la ley, cualquiera que sea su filiación, asestará un primer golpe a aquel modelo tradicional, pero entonces lo biológico, como natural, cobrará incluso mayor protagonismo, posibilitando la investigación de la paternidad y siendo el dato biológico un criterio decisivo en la atribución de la filiación paterna.

Será la adopción quien pondrá a prueba la verdad biológica, como elemento constitutivo de la paternidad/maternidad, situando el elemento volitivo como criterio determinante para la atribución de la condición de padre y/o madre, supliendo el derecho los inexistentes lazos biológicos por iguales vínculos jurídicos a través de sus ficciones. Los vínculos jurídicos que se establecen en materia de adopción permitirán combinaciones distintas a las que permitía la familia natural, entre ellas la creación de familias con hijos de personas del mismo sexo, un vínculo inexistente en la filiación natural. Los efectos de la transgresión de la diferenciación sexual, como parte del orden simbólico familiar, pretenderán mitigarse justificando la existencia de unos vínculos jurídicos carentes de referencia biológica alguna en la protección de órdenes familiares diversos, con criterios de igualdad, y en el interés superior del menor. Ahora bien, la sexualidad y la reproducción siguen estando unidas en el acto procreativo, otra cosa es el ejercicio de las funciones parentales.

Sin embargo, para cuando el derecho reconoce vínculos de filiación a parejas del mismo sexo ya puede apreciarse una gran separación entre la procreación y sus procesos naturales. El proceso de procreación es cada vez menos natural y más consciente, problematizado, planificado y controlado, en palabras de Gunter Grass (5), los partos son, sobre todo, "mentales"2, protagonizados por la voluntad del hijo deseado,

\footnotetext{
2 El autor aborda las diferentes formas en que se afronta la paternidad y la maternidad en el mundo y lo hará a propósito de un viaje a Asia, en el verano de 1980, de una pareja de profesores, Harm y Dörte, en el que se plantean la conveniencia o no de tener un hijo.
} 
no por una mera consecuencia natural derivada de la práctica de relaciones sexuales. La sexualidad no va unida necesariamente a la reproducción, para que esta unión se produzca es preciso que se complemente con la voluntad de procrear.

Sólo faltaba para quebrar la unidad naturaleza-cultura en el ámbito familiar, que la base natural humana de la procreación entrase en el horizonte de la disponibilidad técnica y de la conquista científica, para que la voluntad de procrear se desligase de la sexualidad como referente natural de la reproducción $(6)^{3}$. Entonces, se dirá que las posibilidades de reproducción en manos de la ciencia sustituyen "el calor de los cuerpos por la frialdad de los laboratorios", disocian "el amor conyugal y el don de la vida" y, en última instancia, provocan la "objetivación del hijo", quien antes que "sujeto amado fue objetivo y fruto del conocimiento de quienes tuvieron todo el poder sobre él" (7).

Si, por un lado, la intervención de la ciencia y la técnica en la reproducción han contribuido a desdibujar las huellas del tradicional orden simbólico de la familia construido sobre el orden natural de la procreación; por otro lado, paradójicamente, permiten retornar, a lo natural. Como resultado del proceso de procreación médicamente asistido, la ciencia ha conseguido disociar, combinar y fragmentar elementos y fases de la reproducción que la naturaleza mantenía unidos, corrigiendo o sustituyendo aquellos elementos o fases disfuncionales y tratando de preservar aquellos otros que sí funcionan naturalmente, de tal manera, que el resultado y el procedimiento de reproducción artificial sea lo más parecido posible a un proceso de reproducción natural.

Con la preservación del vínculo genético, con al menos uno de los padres, la ciencia y la técnica se intenta aproximar a la naturaleza y cuando no es posible se adoptan "estrategias de ocultamiento, invisibilidad, clandestinidad y secretismo". Así por ejemplo, si se recurre a la donación de gametos se busca la similitud fenotípica del donante anónimo con el futuro padre o madre, para que con el parecido se pueda seguir manteniendo un patrón de identidad respecto a los padres de deseo que la genética no sustenta (8). De tal manera, que mientras los procesos naturales se "desnaturalizan" en el laboratorio, con la búsqueda de las similitudes fenotípicas se pretende que la

\footnotetext{
${ }^{3}$ Ya la medicalización del embarazo y el parto hace que desaparezca en el proceso de gestación la idea de una naturaleza pura, para convertirse en un proceso administrado por expertos. Con las técnicas de reproducción asistida la idea paternidad/maternidad tradicional y la reproducción se convertirán en dos fenómenos independientes.
} 
naturaleza sea "un espejo en que mirarse, aunque sea de soslayo" (8) 4 . Paradójico puede resultar también la reivindicación del derecho al hijo, mientras pretenden ser fortalecidos los derechos del hijo, cuando se están tomando importantes decisiones anticipadas sobre ese futuro hijo que permanece ajeno a todo el proceso (9).

La ciencia ha conseguido manejar de forma flexible lo natural y lo cultural, a través de distintas posibilidades de uso y combinaciones de sustancias corporales -semen, óvulos y útero- que permiten distribuir identidades y pertenencias múltiples (10). Una flexibilidad que denota la fragilidad, por lo que a la familia se refiere, de la unión entre naturaleza y cultura, que ha provocado que algunas predicciones sobre terribles males futuros se recrudezcan en discursos que recuerdan el terrible destino del doctor Frankenstein, y su disgregadora osadía que le persigue y castiga, o la sociedad deshumanizada que relata Huxley (11) en Un mundo feliz.

Sin embargo, la ciencia y la tecnología no determinan por sí solas un rumbo, al margen de las necesidades y exigencias que se producen en la sociedad y de lo que se pueda considerar permisible o aceptable (11). En los avances científicos hay mucho de humano; junto a la ambición científica, con todo lo humano que contiene, las técnicas de reproducción humana asistida suponen un remedio contra la esterilidad y el sufrimiento humano, además de una explosión de posibilidades y oportunidades en el ámbito de la voluntad y decisión humana en torno a la familia.

El sufrimiento humano que provoca la esterilidad es magistralmente reflejado por Federico García Lorca (12) en su obra Yerma ${ }^{5}$. El drama de una mujer que no tiene hijos y que se describe como "marchita", que maldice a un cuerpo que no le responde a su deseo, generándola un dolor que "ya no está en las carnes", sino en el alma (12). Una mujer que para mitigar su dolor está dispuesta a hacer lo que sea que pueda cambiar aquel destino, aunque sea clavarse "agujas en el sitio más débil de mi cuerpo"(12). Un dolor que se agrava en una sociedad que le muestra toda su incomprensión, al hacerle

\footnotetext{
4 Junto a la similitud fenotípica del donante, algunas otras decisiones normativas como las que afectan al carácter anónimo de las donaciones o la confidencialidad de todo un proceso que, salvo excepciones, no reconoce el derecho del hijo a conocer sus orígenes biológicos, parece estar dirigido a conseguir un resultado lo más parecido posible al de un proceso natural.

${ }^{5}$ Una Yerma que no concibe el mundo de una mujer sin un hijo: "Lo tendré porque lo tengo que tener. $\mathrm{O}$ no entiendo el mundo". Un drama vivido y afrontado de forma muy diferente por hombres y mujeres. Mientras Juan -el marido de Yerma- le manifiesta a su esposa que ya casi está olvidando el problema, ella le contesta: "Pero yo no soy tú. Los hombres tienen otra vida...; las mujeres no tenemos más que ésta de la cría y el cuidado de la cría"
} 
sentirse "ofendida, ofendida y rebajada hasta lo último" (12). Ella que sabe que los hijos nacen de un hombre y una mujer, exclama: "¡Ay, si los pudiera tener yo sola!"(12).

Ay si hubiera sabido Yerma que podía tenerlos sola! Que hubiera escrito Lorca (12) si hubiera sabido, como decía Wagner en la obra Fausto de Goethe (13), que "aquello que se consideraba secreto en la naturaleza" podemos "probarlo de modo racional, con osadía, y lo que ella antes organizaba por su cuenta" el hombre puede hacerlo cristalizar, porque "el misterio ha sido desvelado y está a plena luz", "¿qué más queremos?", "¿qué más nos exige el mundo?"(13).

Lo que el mundo exige es que los progresos en materia científica no se desarrollen al margen de las necesidades humanas y sirvan, precisamente, a esas necesidades, con el objetivo de garantizar los derechos de las personas para mejorar la protección y calidad de vida de las familias y los individuos que las integran.

\section{Las fragmentaciones en el discurso de la reproducción}

En el proceso de procreación médicamente asistida se produce, respecto a la reproducción natural, un incremento del espacio de intervención de actores múltiples y diversos, siendo uno de sus principales ámbitos de acción el cuerpo de la mujer y su última finalidad conseguir la anhelada descendencia. Biólogos, médicos, donantes, receptores, moralista y juristas, entre otros, tienen la oportunidad de manifestar, en el ámbito de la reproducción humana, sus distintos intereses en un proceso ahora separable y apropiable en diversas fases. Se ha llegado incluso a señalar que la interferencia en el proceso de reproducción humana de intereses económicos, a través de intermediarios, ha permitido la incursión de la procreación en la lógica de la producción, superándose la división tradicional entre lo productivo y lo reproductivo (14). Al respecto, expresiones tales como "el nuevo negocio global", "el mercado de la reproducción" o "el turismo reproductivo" no resultan ajenas al debate ético y jurídico sobre las técnicas de reproducción humana asistida $(14)^{6}$.

\footnotetext{
${ }^{6}$ Aunque también se ha negado la posibilidad de asimilar la reproducción a la producción, porque "el espíritu de la generación no puede ser el de la producción: las cosas se fabrican, a los seres se les recibe" (15)
} 
Las grandes transformaciones que han producido aquellas múltiples intervenciones en el proceso reproductivo alcanzan a valores, creencias y representaciones, considerados en otros momentos inamovibles e inescindibles, como la maternidad y la paternidad, el cuerpo y la persona o el cuerpo y la mente. Si la reproducción no está ya necesariamente unida a la sexualidad, la paternidad y maternidad biológica no están necesariamente unidas a la paternidad y maternidad social, ni el cuerpo y sus partes se identifican necesariamente con la persona, ni la parte física se considera necesariamente unida a la parte emocional del ser humano.

El uso de las técnicas de reproducción asistida plantea la posibilidad de disociar, fragmentar y jerarquizar distintos aspectos de la paternidad y la maternidad, sometiendo las decisiones sobre la atribución de filiación paterna y materna a una serie de variables inexistentes en la reproducción natural. Así en un proceso de procreación asistida pueden existir un padre genético -donante de semen- y un padre social -quien asumirá las funciones propias de la paternidad-, una madre genética-donante de los óvulos-, una madre gestante -quien desarrolla el embarazo- y una madre social -quien asume la crianza y educación del bebé-. La complejidad de un proceso que admite múltiples variables genera importantes incertidumbres que han de ser reducidas o simplificadas, para conciliar los intereses de todas las personas afectadas: nada menos que padres, madres y su descendencia. Será para ello necesario realizar una valoración sobre la importancia de lo genético, lo biológico y lo social y establecer prioridades en relación a aquellas valoraciones. En definitiva, habrá de valorarse si la genética, que permite transmitir vida, rasgos físicos y mentales, prolongar en la descendencia elementos personales, debe primar, en el orden social, como criterio de identidad personal, sobre la gestación, que permite compartir cuerpos y establecer lazos de apego entre gestante y feto; o si ambos criterios, o uno u otro, deben ceder ante el compromiso de asumir las funciones propias de la paternidad y/maternidad, que implican la crianza, cuidado y educación del individuo, permitiéndole su desarrollo personal (8).

Más allá de las maternidades y paternidades fragmentadas, con el desarrollo de la biotecnología, en asuntos como el trasplante de órganos, la investigación con seres humanos o la fecundación asistida, se ha planteado un proceso de fragmentación del cuerpo, antes unido de forma inescindible e identificado con la persona, su integridad y 
su dignidad. La persona deja de estar encerrada en los confines de un cuerpo que ahora puede ser separado en partes, células, tejido y órganos de las que poder disponer de forma autónoma El cuerpo se deconstruye y reconstruye, dejando de ser una unidad biológica indivisible, para componerse y descomponerse en partes, de las que la persona puede desprenderse voluntariamente, sin que ello afecte ni a su integridad, ni a su dignidad, ni a su condición de persona (16). Bajo tales presupuestos se discute sobre la tradicional indisponibilidad y extracomercialidad del cuerpo humano, para permitir la posibilidad de convertir a partes del mismo en objetos del tráfico jurídico. La cuestión a debatir versará entonces sobre la extensión y los límites de las posibilidades de disposición sobre el propio cuerpo, como un problema cultural más que biológico. Al respecto se han alcanzado algunos consensos, entre los que se incluye, la disponibilidad del propio cuerpo, siempre y cuando no lo sea por motivos económicos. En este sentido, sería el ánimo de lucro lo que comprometería la autonomía y libertad del sujeto sobre las decisiones relativas a su cuerpo o a partes del mismo, no tanto la integridad o la dignidad inherente a la persona ${ }^{7}$.

Como colofón de las escisiones y fragmentación, en la reproducción asistida se ha planteado la posibilidad de separar cuerpos y mentes, la parte física y emocional del ser humano. A lo largo del proceso reproductivo no sólo se comprometen aspectos físicos, sino también psicológicos y emocionales, tradicionalmente considerados unidos, especialmente en relación a la maternidad. Sin embargo, la libertad reproductiva, sobre la base del reconocimiento de la autonomía y la capacidad de decidir sobre el propio cuerpo y sus funciones, ha permitido presuponer que las personas implicadas en la reproducción son capaces de tomar decisiones racionales, a partir de un cálculo sobre costes y beneficios por sus servicios en las distintas fases del proceso. En este cálculo se llegan a obviar las implicaciones emocionales posibles, e incluso probables, sobre el

\footnotetext{
${ }^{7}$ El Convenio para la protección de los derechos humanos y la dignidad del ser humano con respecto a las aplicaciones de la Biología y la Medicina (Convenido relativo a los derechos humanos y la biomedicina, cuya ratificación por España fue publicada en el BOE, núm. 251, de 20 de octubre de 1999, páginas 36825 a 36830 ) hecho en Oviedo el 4 de abril de 1997, en el capítulo VII, artículo 21, establece que "el cuerpo humano y sus partes, como tales, no deberán ser objeto de lucro". Por su parte, la Carta de los Derechos Fundamentales de la Unión Europea, establece que en el marco de la medicina y la biología se respetará "la prohibición de que el cuerpo humano o partes del mismo en cuanto tales se conviertan en objeto de lucro". Art. 3. 2, Diario Oficial de las Comunidades Europeas 18.12.2000 (2000/C 364).
} 
propio resultado de la prestación de estos servicios y de disposición sobre partes del cuerpo: un nuevo ser humano (17).

\section{La escisión de la maternidad}

\section{La maternidad subrogada ¿Madre solo hay una?}

La maternidad subrogada -también llamada maternidad de sustitución, gestación por otro o vientre de alquiler- ha sido considerada como el "ejemplo límite de los retos de las procreaciones asistidas" (10). En virtud de esta práctica una mujer gesta un bebé a cuya maternidad renuncia, en favor de otra $u$ otras personas que se comprometen a asumir la paternidad y/o maternidad. En la maternidad subrogada pueden estar presentes el mayor número de intervinientes y posibles variables en un proceso reproductivo. La persona que pretende asumir la paternidad social puede ser el padre genético o no, en el caso de que se utilice semen de donante. La mujer que se compromete a asumir la maternidad social puede además ser madre genética, aportando sus óvulos en la fecundación; o puede asumir tal condición la propia gestante, si se utilizan sus propios óvulos; también la maternidad genética puede proceder de una tercer mujer, donante de óvulos. Es un recurso que, además, permite la posibilidad de tener descendencia, sin necesidad de recurrir a la adopción, a todas las modalidades familiares, incluidas las formadas por dos varones. Otras peculiaridades propias de esta modalidad reproductiva son destacables, como la intervención de intermediarios que propician los acuerdos entre madres gestantes y quienes desean ser padres y/o madres; las situaciones de desigualdad entre unas y otros, con los consiguientes riesgos de explotación de mujeres y tráfico de bebés; o el largo periodo de tiempo que supone la intervención en el proceso reproductivo de la mujer gestante y los posibles cambios de intención de las partes durante el mismo. Finalmente, siendo la práctica que introduce más variables en el proceso reproductivo y, por tanto, mayor número de elecciones, en cuanto a la determinación de identidades y pertenencias, es también la práctica que mayor conflictividad puede generar, de ahí que el proceso no sea ajeno a la intervención de abogados, jueces o encargados de registros civiles.

Un escenario amplio y complejo, en el que la diversidad de deseos, intenciones expectativas e intereses elevan casi a una nueva dimensión toda la problemática 
insertada en la reproducción asistida: la pérdida de elementos naturales de la familia, las paradojas en torno a tal desnaturalización, la fragmentación de la maternidad, de los cuerpos y del cuerpo y de la mente. Un escenario en que se intensifica la problemática ética y jurídica centrada en el orden simbólico de la mujer, la maternidad y la familia, en un marco de reconocimiento, protección y garantía de derechos, que incide de forma muy especial en los derechos de la mujer y de la infancia. Todo ello en un contexto global en el que, propiciado por la existencia de regulaciones diferenciadas, es difícil impedir que se traspasen las fronteras con el objetivo de eludir los límites establecidos en las normativas internas ${ }^{8}$.

En comparación con el uso de otras técnicas en la reproducción que permiten la fragmentación de la paternidad e incluso de la maternidad, en el caso de la subrogación maternal se pone de manifiesto que el hecho de que la maternidad pueda separarse de la gestación hace que se tambaleen los cimientos, reales o imaginarios, de las raíces mismas del proceso de reproducción, su lado natural, indisoluble, permanente y universal entre las madres y sus bebés, en los que se entreteje "la lógica del instinto maternal" (18). Desde el punto de vista simbólico, la vinculación de la maternidad a lo natural, a la propia identificación con la sexualidad femenina, sus roles culturales y vínculos afectivos perviven en el imaginario colectivo con gran intensidad. Hasta tal punto que, en lo que afecta a la gestación, no se hará posible escindir la condición de madre gestante de la madre social, ni fragmentar el cuerpo en partes disponibles, ni separar el cuerpo de la mente, sin afectar a la dignidad de la mujer, del hijo que está por nacer y de la propia gestación.

En efecto, si el elemento volitivo ha ido ganando terreno a la verdad biológica como criterio de atribución de la filiación, como pone de manifiesto la respuesta jurídica al caso de la donación de gametos, tal tendencia no se confirma en el supuesto de la maternidad subrogada. El desarrollo de la gestación le proporciona a la mujer gestante

\footnotetext{
${ }^{8}$ Aunque la gestación en favor de otra persona no es una práctica novedosa, sí lo es el contexto en que se produce actualmente. Es una práctica antigua de la que la biblia da cuenta. Sara dijo a Abraham: "Mira, el Señor me ha hecho estéril: así que acuéstate con tu esclava, a ver si por medio de ella puedo tener hijos (Génesis, 16, 14). Raquel dijo a Jacobo: "Aquí tienes a mi esclava Bilhá. Únete a ella y que dé a luz sobre mis rodillas. Así, por medio de ella, yo también podré tener hijos" (Génesis, 30,3). No es tampoco nuevo que a raíz de estos relatos bíblicos una de las mayores preocupaciones que genere la maternidad de sustitución es la instrumentalización del cuerpo de la mujer, nótese que en estos pasajes la mujer gestante es una esclava.
} 
una apariencia de madre que no admitirá, en muchos ordenamientos, prueba en contrario, no permitiendo su renuncia a la atribución legal de la maternidad, aunque no sea su voluntad. En forma paralela a este tratamiento jurídico de la mujer que desarrolla la gestación, resultará jurídicamente desconocida aquella que manifestó su voluntad de asumir la maternidad, incluso cuando aporta sus óvulos en el proceso de reproducción. La madre genética será así tratada como si fuera una donante, pese a que esa no fue su voluntad y que la donación no tiene carácter anónimo. Y es que la gestación no puede permanecer oculta, a diferencia de lo que sucede en la donación de gametos, no pueden borrarse las huellas de un embarazo. La gestante será depositaria de una experiencia concreta de maternidad, erigiéndose en el último símbolo, que se necesita preservar, de todo lo natural contenido en el acto de reproducción. La certeza de la maternidad atribuida por el parto, se erige también en el último símbolo que permite la unión entre la familia natural y la familia legal (4).

Todo un universo simbólico que servirá para fijar como límites al acuerdo entre las personas, por lo que a la reproducción se refiere, una parte del cuerpo mujer -el útero- y una fase proceso reproductivo -la gestación-, aunque el cuerpo haya dejado de identificarse con la persona, que puede disponer de sus partes sin que afecte a su dignidad, siempre que no exista ánimo de lucro. De hecho, en el caso de la donación de gametos no se ha planteado con gran intensidad el debate sobre si los donantes, que aportan material genético, son tratados o no como meros productores de sustancias y, por ello, son o no afectados en su dignidad, o si siendo estas sustancias partes del cuerpo están o no fuera del comercio, salvo para descartar el lucro, ni siquiera se descarta, antes bien se contempla, la posibilidad de que exista una compensación económica por estos servicios reproductivos. Pese a que pueda por esta vía mediar precio, los espermatozoides o los óvulos ni se alquilan, ni se compran, ni se venden, se donan. Sin embargo, en el caso de que en el proceso reproductivo el órgano implicado sea un útero ajeno y el servicio que se preste sea el de gestante, el debate se intensifica. La mujer, en tal supuesto, parece comprometer no sólo el útero, sino a través de él, su cuerpo entero, más aún, su propia condición de mujer. Entonces, aunque no medie precio, el útero no se dona, se "alquila", y tiende a situarse fuera del comercio de los hombres. Desde esta perspectiva, la gestante se vería afectada en su dignidad, 
porque su cuerpo y toda su persona sería instrumentalizada al servicio de otras personas. Pero también atentaría contra la dignidad del hijo, convertido por el acuerdo de subrogación maternal en un mero instrumento al servicio del deseo de los padres, o una propiedad objeto de comercio, evidenciado en el acto de entrega posterior a su nacimiento (19), (20), (21) ${ }^{9}$.

Si la mujer, en el caso de la maternidad, no puede separarse de una parte de su cuerpo que parece identificarle con su propia condición de persona y de mujer, tampoco podrá desligarse su función reproductiva, como gestante, de la afectividad que en la gestación se desarrolla y que la une al bebé gestado. Una gestante que cede la maternidad a otra persona aparece como una mercenaria dispuesta a abandonar a sus hijos y permitirlo degradaría la gestación a una "pura función de fabricación" (22). Los estrechos lazos afectivos que vinculan a gestante y feto parecen imposibles de olvidar después del nacimiento y degradan, no sólo a la maternidad en sí, también a la mujer gestante y al desarrollo del bebé, a quien además del elemento afectivo se le privaría de elementos básicos de su identidad $(23)^{10}$.

\section{El contrato de maternidad subrogada}

Tratando la disciplina del contrato, como marco jurídico que pudiera dar cobertura a la maternidad subrogada, Shalev y Pateman (24) sintetizan dos posiciones diversas y

\footnotetext{
${ }^{9}$ La sustracción a la autonomía de la voluntad de los negocios del derecho de familia -por razones de interés público, imperativos éticos y función social-, la dignidad de la mujer -en tanto manipulación del cuerpo femenino- y la protección de los derechos de los hijos, son los argumentos sostenidos para negar la posibilidad de someter la maternidad al ámbito de los negocios jurídicos.

10 La maternidad subrogada, según la Instrucción Donum Vitae sobre el respeto de la vida humana naciente y la dignidad de la procreación, de 22 de febrero de 1987 instaura en detrimento de la familia la división entre los elementos físicos, psíquicos y morales que la constituyen. Es, por ello, considerada como contraria a la unidad del matrimonio y a la dignidad de la procreación humana; representa una "falta objetiva contra las obligaciones del amor materno, de la fidelidad conyugal y de la maternidad responsable, ofende a la dignidad y al derecho del hijo a ser concebido, gestado, traído al mundo y educado por los propios padres". Puede verse el contenido íntegro de la instrucción en: http://www.vatican.va/roman_curia/congregations/cfaith/documents/rc_con_cfaith_doc_19870222_respectfor-human-life_sp.html.

También en la adopción al menor se le desvincula de la madre gestante, aunque se justifica en su propio interés. Pero en la maternidad subrogada los acuerdos se realizan antes de la concepción y no después del nacimiento del bebé, como en la adopción. El que la maternidad de sustitución pueda suponer un fraude a las normas sobre adopción es también una de las razones esgrimidas en contra de su licitud. Cfr. FÁBREGA RUIZ, C. F., Biología y filiación. Aproximación al estudio de las pruebas biológicas de paternidad y de las TRA, Comares, Granada, 1999, p. 115.
} 
enfrentadas ${ }^{11}$. En ambos casos, se trata de la fragmentación del cuerpo, del cuerpo y la mente, de la maternidad, de la incidencia que tales escisiones tienen en la construcción del sujeto femenino como persona sexuada y del valor intrínseco o extrínseco de la capacidad de procrear.

Las cuestiones a discutir sobre la validez o la conveniencia de regular a través de la modalidad contractual el hecho de que una mujer lleve a cabo una gestación por encargo de otra u otras personas, con la finalidad de entregar, concluida la gestación, a un bebé, se centran en la posibilidad de disponer de una parte del cuerpo de la mujer su útero-, a través del cual se presta un servicio concreto -la gestación-, siendo una de las obligaciones principales para la mujer gestante la entrega de una persona -el bebé que está por nacer cuando se realiza el acuerdo-.

\section{Una forma renovada del contrato sexual}

Para Pateman (25) el cuerpo y la persona no son idénticos, sin embargo, son inseparables, no siendo posible la fragmentación del cuerpo sin afectar a la esencia de la persona. En el mismo sentido, aunque la persona no se subsume por completo en su sexualidad, la identidad es inseparable de la construcción sexual de la persona. Así pues, menos aún son separables de la condición de persona aquellas partes del cuerpo que configuran la identidad del ser humano como ser masculino o femenino, es decir, que configuran la esencia de la persona sexuada. Existe, por tanto, una relación integral entre el cuerpo, sus partes, la sexualidad y la identidad como persona.

Siendo, en esencia, la persona un ser sexuado, como no es posible desligar de la misma aquellas partes y capacidades físicas que la identifican con su sexo, tampoco es posible desligarla de las capacidades emocionales que configuran también su identidad personal. A estos efectos, tanto el útero como la capacidad reproductiva de la mujer es determinante de la construcción del sujeto femenino, por tanto, un contrato que tenga

\footnotetext{
${ }^{11}$ Dos posiciones totalmente contrarias respecto a la maternidad subrogada, que resultan familiares en relación a otras que desde el feminismo se han mantenido sobre las técnicas de reproducción asistida. Algunas consideran dichas técnicas como liberadoras para las mujeres, mientras otras las entienden como una nueva forma de dominación y opresión sobre ellas. Al respecto es interesante CHARLESWORTH, M., La bioética en una sociedad liberal, trad. M. González, Cambridge University Press, 1996, pp. 109-123. Ver también Puigpelat Martí, F., "Feminismo y técnicas de reproducción asistida", Aldaba, № 32, 2004, pp. 63-80.
} 
como referencia al útero, afecta a un órgano que configura en esencia la identidad femenina. Si además involucra a la maternidad, afecta a una singular capacidad fisiológica, emocional y creativa del cuerpo de la mujer. La relación de una mujer con su útero o con la gestación no puede ser una relación externa de propiedad o de prestación de servicios, ya que es intrínseca a su propia condición de mujer, su cuerpo y su capacidad reproductiva, e incide sustancialmente en su propia persona, en su condición de mujer (25).

Por su parte, la maternidad, además de ser una específica capacidad fisiológica de la mujer, es una singular capacidad emocional ligada a la condición femenina. Si no puede escindirse del sujeto femenino aquella parte física que le hace en esencia mujer, tampoco se le puede privar de la parte emocional que le identifica con su sexo y que permite que la relación establecida durante la gestación, entre mujer y feto, sea cualitativamente diferente a cualquier otra. La condición de madre es, por tanto, coincidente con la de gestante, tanto referido al aspecto fisiológico como al emotivo.

La continuidad entre el cuerpo femenino, las emociones y la maternidad implica que negociar sobre la capacidad de gestar es atentar contra la propia integridad e identidad personal; es negar valor a la capacidad corporal única de la mujer, es tornar irrelevante la propia condición de mujer. En última instancia, supondría permitir a los varones apropiarse del cuerpo de la mujer y, a través de su cuerpo, de su propia persona. No es baladí que el mismo contrato que pudiera hacer perder a la mujer gestante la condición de madre, sería suficiente para que un hombre se convierta en padre, instrumentalizando a una persona -mujer- al servicio y para los fines de otra persona-varón (25). De esta manera, reconocer política o jurídicamente autonomía para contratar sobre la capacidad de gestar es un modo de apropiarse de las mujeres, de revitalizar bajo nuevas formas el patriarcado.

La sombra de Robert Filmer, dirá Pateman (25), planea sobre la maternidad subrogada, regresando con él una parte del patriarcado clásico: la simiente del varón llena la vasija vacía de la hembra, trayendo con su fuerza creativa una nueva vida al mundo, que es de su propiedad y lo convierte en padre, a la vez que priva de la 
condición de madre a la portadora de aquella vasija ${ }^{12}$. La maternidad subrogada se ha convertido en "un ejemplo dramático" de la reaparición de nuevas fórmulas contractuales que permiten el acceso y el uso de los cuerpos de las mujeres (25).

\section{El reconocimiento de la plena autonomía de la mujer}

Para Shalev (26), por el contrario, la condición de persona es independiente de los órganos que configuran la sexualidad y sus capacidades específicas, incluida la capacidad reproductiva. Partiendo de este presupuesto inicial, es perfectamente factible fragmentar el cuerpo en distintas partes, sin afectar a la condición de persona, sea hombre o mujer; es posible separar el cuerpo de las emociones, aunque tales emociones tengan como base la gestación; finalmente, puede desligarse la paternidad/maternidad biológica de la social, sea cual sea la participación que hombres y mujeres realicen en el proceso reproductivo. Las consecuencias jurídicas de todas estas fragmentaciones y separaciones, pueden ser sometidas a la disciplina del contrato de maternidad subrogada, en el que se debe permitir atribuir valor económico a la capacidad reproductiva de la mujer, sin que ninguno de los extremos negociados comprometa necesariamente la autonomía y libertad de las partes que suscriben el acuerdo.

La cooperación en la actividad procreativa es el nuevo marco en el que se desarrolla una nueva cultura de la reproducción y en el que se llevan a cabo los acuerdos de maternidad subrogada. En este contexto, es posible disociar paternidad/maternidad biológica y social, órganos, capacidades y emociones de todas las personas intervinientes en el proceso. La base que permite tales disociaciones y aquella cooperación es la relación entre sujetos adultos, autónomos, responsables y con plena capacidad de ejercitar, de modo racional y autónomo, elecciones sobre sus capacidades y posibilidades reproductivas y asumir sus responsabilidades. En este ámbito general cooperativo es indiferente que la participación del sujeto en el proceso

\footnotetext{
12 Sólo faltaba ya que, "como vuelta de tuerca", pueda presentárselo a su esposa como "un último regalo". Interesante al respecto es señalar que en nuestro derecho, al amparo de la nulidad de pleno derecho del contrato de maternidad subrogada, el varón que contrata puede reclamar su paternidad, si es padre biológico. En cambio, la mujer no gestante es ignorada por el derecho, aunque haya aportado su material genético.
} 
sea como donante de esperma, donante de óvulos, receptora de uno u otros, o como gestante.

Teniendo en cuenta estas consideraciones, diferenciar la posición de la mujer gestante en el proceso procreativo, para negarle la capacidad de intervenir en el mismo, y asumir la responsabilidad que ello conlleva, es una actitud paternalista que refuerza la imagen tradicional de la mujer impregnada en la subjetividad de su útero (26). Pero la posesión de un útero, y de las capacidades a tal órgano asociadas, no permiten establecer la identidad de una persona, hasta el punto de privarle de la capacidad de contraer compromisos referidos a esta parte del cuerpo. Por el contrario, el útero es una parte más del cuerpo de la mujer, cuya propiedad le permite ofrecer un servicio personal de procreación: la gestación. Así pues, la plena y libre disposición de una parte de su cuerpo, aunque sea el útero y su capacidad de gestar -0, precisamente, porque es el útero y su capacidad de gestar- refuerza la autonomía y capacidad de decisión de la mujer.

Además, reconocer a la mujer su plena condición de persona racional con autonomía para tomar decisiones, significa reconocerle también capacidad para gobernar sus emociones, aún estando embarazada, y asumir las responsabilidades contraídas. Por otro lado, aún admitiendo la existencia de vínculos emocionales entre gestante y feto, no necesariamente han de derivarse de tales emociones vínculos legales de cuidado, ya que es perfectamente posible desvincular los vínculos jurídicos de los emocionales. Que una mujer esté vinculada por un acuerdo de gestación voluntaria en favor de otra persona, significa que no tendrá responsabilidad en la crianza y educación del bebé, no que no se preocupe por su destino. Es más, derivar de aquellos vínculos emocionales vínculos jurídicos es una forma de opresión propia de los parámetros culturales tradicionales de la relación maternal (26). Al respecto, se ha de tener en cuenta que, más allá de las relaciones maternales, las relaciones afectivas y familiares han dejado de ser una "isla de emotividad", para adentrarse en un mundo dominado por la impersonalidad de la economía y la política; circunstancia que alcanza a una actividad procreativa, en la que la gestación y el desarrollo en la vida del niño han salido ya del círculo estrictamente familiar y emotivo, a través de la intervención, entre otros, de médicos, biólogos, educadores, agentes sociales y juristas (26). 
Como consecuencia de aquellas tomas de posición, Shalev sostiene que la cooperación en el proceso procreativo debe ser determinada en un contexto contractual, de acuerdo con las deliberaciones de las partes adoptadas antes de la concepción. En este sentido, el acuerdo de subrogación puede ser calificado como un contrato para la venta de servicios personales de procreación o un contrato a favor de tercero: el niño que va a nacer (26). En relación a las objeciones relativas a la dignidad del bebé y su posible comercialización, se señala que en la maternidad subrogada el interés está centrado en el valor intrínseco de la actividad reproductiva, cuya capacidad corresponde a la mujer, no en el producto final, cuyo interés resulta mejor protegido si quienes cooperan en el proceso reproductivo asumen sus responsabilidades desde el inicio del mismo.

Consciente, no obstante, de los riesgos inherentes a este tipo de contratos, en relación a la explotación de las mujeres y de los menores, se afirma que el peligro real de la subrogación está en los fines económicos o políticos que persiguen las partes extrañas al acuerdo. Por eso, es importante proteger la esfera de autonomía del individuo, siendo el contrato, como modelo no jerárquico y descentralizado de potestad normativa, el instrumento que mejor favorece la cooperación entre sujetos autónomos, dando su regulación respuesta jurídica a los fallos en la cooperación, como mejor garantía también del interés del menor.

En cuanto a la regulación de las contraprestaciones económicas de este servicio reproductivo, el fin de evitar el peligro de explotación no ha de ser una razón de prohibición, sino de estipular condiciones de desarrollo del contrato que estén dirigidas a evitar que aquella explotación se produzca. Se afirmará, incluso, que la máxima manifestación de libertad se da cuando la madre subrogada recibe un valor económico por su actividad procreativa, porque la mujer es un ser consciente, moral, social, política y económicamente y de la misma manera que no se la puede aislar de una parte de su propia existencia, tampoco ignorar el valor de su poder de procreación. Más si se tiene en cuenta que la actividad procreativa es el recurso económico central de cualquier sociedad, resultando, por ello, paradigmático que se le pretenda privar de valor económico. 


\section{Otras fórmulas de acuerdo sobre la maternidad sub-rogada}

En las dos posiciones anteriores se ha visto reflejada la problemática que encierra la maternidad subrogada en relación a las personas que intervienen en la procreación, en las instituciones que se ven afectadas -familia, mercado, contrato-, en los derechos e intereses en juego y, sobre todo, en la centralidad del papel de la mujer en todo el proceso.

Desde estas perspectivas, teniendo en cuenta los riesgos que la maternidad subrogada conlleva, se ha señalado que las situaciones, en que esta opción se puede plantear, son tan amplias y variadas que no se puede suponer per se su licitud o ilicitud. Un primer aspecto a tener en consideración es que en esos casos normalmente no hay una única verdad biológica para asentar la maternidad -es frecuente que se geste un embrión ajeno-. En segundo lugar, aunque probablemente haya una situación de desventaja entre la mujer gestante y quienes hacen el encargo, no se puede deducir de tal situación un vicio de consentimiento, ni presuponer que obligatoriamente haya una situación de necesidad económica en la gestante, como único motivo para aceptar participar en el proceso reproductivo. Tampoco puede erigirse en un argumento decisorio, ni suponer en todo caso, que la separación entre la gestante y el bebé conlleve una situación gravemente traumática para ambos (9).

Es innegable, por otro lado, que estas y otras situaciones pueden producirse y que han de ser valoradas para abordar una regulación respetuosa y garantista de los derechos de las personas implicadas en el proceso reproductivo, especialmente aquellas que se encuentran en una posición más vulnerable: las mujeres gestantes y los bebés. Partiendo de estos presupuestos, se ha señalado que, tanto el principio moral según el cual ninguna persona puede convertirse en un instrumento para fines ajenos, como el principio jurídico que prohíbe la comercialización del cuerpo, dirigidos a tutelar la dignidad de la mujer gestante, impiden aplicar a un acuerdo sobre la gestación la lógica del contrato. De tal manera que la maternidad subrogada sólo sería admisible bajo la forma de donación, siempre dejando a salvo el derecho de la gestante a desistir hasta el momento del nacimiento del bebé (27).

Se han propuesto también modelos de regulación flexible, que sean respetuosos con las intenciones de los sujetos implicados. Modelos que deberían excluir 
intervenciones jurídicas que supongan o propongan una paridad entre varones y mujeres, que reconozcan y potencien la autonomía y la responsabilidad femenina en las elecciones procreativas, que no constriñan a la gestante a los acuerdos adoptados en el momento de la concepción o la implantación de los embriones, y en los que la atribución de la paternidad jurídica sea el resultado de una decisión de la mujer gestante y no una decisión, en caso de conflicto, sostenida por el criterio de la paternidad biológica (17).

\section{De los valores en conflicto, a la diversidad normativa y al hecho de los acuerdos de maternidad subrogada}

Se han tratado distintos valores en relación a la reproducción asistida, en general, y a la maternidad subrogada, en particular, de lo natural y cultural en la procreación y en la familia, de la persona y de su dignidad, del valor del cuerpo humano y de sus partes y de la entrada de los servicios reproductivos en el mercado, donde los intereses adquieren protagonismo junto a los valores.

Desde la perspectiva de distintos valores e intereses en conflicto, la legislación sobre la maternidad subrogada es abordada de muy diferente manera en los distintos países (28), (29). En muchos no está siquiera tratada y quienes lo regulan han optado, bien por la prohibición en cualquier caso y situación ${ }^{13}$, o por su admisión con requisitos más o menos amplios ${ }^{14}$.

La diversidad de respuestas jurídicas a esta problemática supone un nuevo reto para aquellos ordenamientos que la prohíben, porque en un mundo globalizado no resulta difícil traspasar las fronteras físicas que acercan a las parejas e individuos hacia

\footnotetext{
${ }^{13}$ Es el caso de la mayoría de los países europeos, como por ejemplo Francia, Alemania, Austria, Suiza, Italia o España. La regla general es en estos países la nulidad de los acuerdos de maternidad subrogada y el criterio del embarazo y del parto para atribuir la filiación materna. Véase el artículo 16. 7 del Código civil francés; el artículo 1.7 de la Ley federal alemana de 13 de diciembre de 1990; el artículo 4.3 de la ley federal austriaca de 1 de julio de 1992 sobre reproducción asistida; el artículo 4 de la ley federal Suiza sobre procreación médicamente asistida; el artículo 4.3 de la ley sobre procreación médicamente asistida italiana de 19 de febrero de 2004; y el artículo 10 de la ley española de 26 de mayo de 2006 sobre técnicas de reproducción humana asistida.

${ }^{14}$ En Grecia, la Ley 3089/2002 sobre Asistencia Médica a la Reproducción Humana precisa para los acuerdos de maternidad subrogada autorización judicial y que no tengan fines lucrativos. En Reino Unido, según Surrogacy Arragementes Acts, 1985, los acuerdos son homologables judicialmente, siempre que no tengan fines lucrativos, se realicen sin intervención de intermediarios y no se publiciten. En Rusia se exige que la gestante tenga ya un hijo sano y goce de buena salud. En Israel los acuerdos están regulados por la ley 5746 de 1996; Canadá, Australia, Sudáfrica, India y algunos Estados de los EE.UU, cuentan también con regulación sobre los acuerdos de maternidad de sustitución.
} 
su anhelada descendencia. De esta manera, aquella última frontera natural de la familia, representada en la maternidad de la gestante, es cada vez menos infranqueable, al encontrar lugares de paso hacia el reconocimiento de efectos jurídicos derivados de las prohibiciones establecidas en el derecho propio. El reconocimiento legal de la filiación en favor de los padres de deseo, en aras al interés superior del menor, se erige en el camino y en el fin de un derecho al que le resulta cada vez más difícil imponerse a los hechos. Al respecto, la situación en España puede servir de ejemplo.

\section{De la nulidad de los contratos de maternidad subrogada al reconocimiento de efectos jurídicos}

En España, el artículo 10 de la Ley 14/2006, de 26 de mayo, sobre técnicas de reproducción humana asistida, declara "nulo de pleno derecho el contrato por el que se convenga la gestación, con o sin precio, a cargo de una mujer que renuncia a la filiación materna en favor del contratante o de un tercero", determina que la filiación se establecerá por el parto y deja a salvo la "acción de reclamación de la paternidad respecto del padre biológico, conforme a las reglas generales".

La tradicional certidumbre y unidad de la maternidad, que preside nuestro derecho de filiación, junto con otras valoraciones morales y jurídicas, profundamente arraigadas en nuestra cultura, justifican la determinación legal de la filiación materna por el parto. Se imponen así razones referidas a los riesgos que estos acuerdos supondrían para producir o incrementar la explotación de mujeres y niños, la mercantilización del cuerpo de la mujer, la vulneración de su dignidad y la del bebé o la protección de la integridad física y moral de ambos. Quedan relegadas otras razones, como el respeto a la verdad biológica, en el caso de que los óvulos no procedan de la madre gestante, o a la voluntad y libertad de quienes suscriben el acuerdo, que avalarían soluciones diversas.

Sin embargo, pese a la nulidad de pleno derecho de los acuerdos de maternidad subrogada proclamada en el derecho español, es una práctica utilizada fuera de nuestras fronteras por ciudadanos españoles. Es un hecho que algunas personas, con recursos económicos, realizan acuerdos de maternidad subrogada en el extranjero, para una vez nacidos los niños, y determinada a su favor la filiación, pretender en los mismos términos su inscripción en el registro civil español. La propia legislación nacional mitiga 
los efectos de aquella nulidad. De un lado, no prevé ninguna sanción para quienes intervengan en tales prácticas y, de otro lado, deja a salvo la acción de paternidad del padre biológico, pudiendo en tal caso, previo consentimiento de la madre gestante, el otro miembro de la pareja, si lo hubiera, adoptar al nacido al amparo del contrato de maternidad subrogada.

Tal situación dio lugar a una pionera Resolución de la Dirección General de Registros y Notariado, de 18 de febrero de 2009, que ordenó la inscripción en el registro consular de dos niños nacidos en California, mediante acuerdo de maternidad subrogada, como hijos naturales de los dos padres que habían suscrito aquel acuerdo. La Resolución entendió que, en este caso, no se trataba de determinar la filiación de los menores, sino de permitir el acceso al registro español de una certificación registral extranjera, en la que constaba el nacimiento y la filiación de los nacidos. Planteada la inscripción en estos términos no procedería la aplicación de las normas sustantivas españolas, sino de las que establecen los requisitos legales para acceder a nuestros registros, siempre que no se produjeran efectos contrarios al orden público español. Orden público que no resultaría afectado, puesto que el ordenamiento jurídico español permite ya la filiación en favor de dos varones, en los casos de adopción, y en favor de dos mujeres, tanto en supuestos de adopción, como cuando se trata de hijos nacidos a través de las técnicas de reproducción asistida. En atención a estas dos consideraciones, lo que no permitiría el derecho español es la diferencia de tratamiento entre hijos adoptados y naturales o la discriminación por razón de sexo.

A mayor abundamiento, se argumentó que rechazar la inscripción supondría la vulneración del artículo 3 de la Convención de Derechos del Niño, que exige atender de forma primordial al interés superior de los menores, cuya traducción al caso concreto, consistiría en garantizar que los niños queden al cuidado de quienes han dado su consentimiento para ser padres y la garantía del derecho de los menores a una identidad única o, lo que es lo mismo, a una filiación que no cambie al cruzar las fronteras. En definitiva, la Resolución consideró que el acceso al registro español de una certificación registral extranjera, que determina la filiación natural en favor de dos padres, no vulnera el orden público internacional español, evita una discriminación por razón de sexo y protege el interés del menor, aunque aquella certificación registral traiga 
su causa en un contrato que la legislación española califica como nulo de pleno derecho ${ }^{15}$.

La inscripción, hecha en virtud de aquella Resolución, fue anulada por la Sentencia del Juzgado de Primera Instancia № 15 de Valencia, de 15 de septiembre de 2010, y confirmada posteriormente por la Sentencia de la Audiencia Provincial de Valencia, de 23 de noviembre de 2011. Ambas decisiones judiciales entienden que el acceso al registro civil español no requiere solo una comprobación formal de la certificación registral extranjera sino que exige, en aplicación del artículo 23 de la Ley del Registro Civil y los artículos 85 y 81 de su Reglamento, que no haya duda sobre la realidad del hecho inscrito, ni de su legalidad conforme a la ley española. Si, por un lado, estiman que el hecho es contrario a la ley española, por otro lado, lo consideran también contrario al orden público español, cifrando la contradicción con el orden público español en la vulneración que, a través de la maternidad subrogada, se produce a la dignidad humana, al derecho a la integridad moral y a la protección integral de madres e hijos ${ }^{16}$.

La Sentencia de la Audiencia Provincial de Valencia fue objeto de recurso ante el Tribunal Supremo, dando lugar a una Sentencia del Pleno desestimatoria del recurso, el 6 de febrero de $2014^{17}$. El motivo del recurso fue la infracción del artículo 14 de la Constitución española, es decir, la vulneración del principio de igualdad, en relación con el derecho a la identidad única y el interés superior de los menores, protegidos por la

\footnotetext{
15 Téngase en cuenta que, al tratar la contrariedad o no al orden público, la cuestión se ha centrado en la filiación a favor de dos varones, pero se ha eludido la cuestión de fondo: si la maternidad subrogada contraria o no al orden público español. Así lo pone de manifiesto Atienza, para quien la solución propuesta en la Resolución es acertada, pero advierte que, en aras a una mayor solidez en su fundamentación, debiera haber incorporado dos aspectos. Primero, que la maternidad subrogada no está expresamente prohibida en nuestro derecho. La nulidad del contrato no equivale a una sanción, ni a que sea necesariamente un acto prohibido, ni jurídicamente ilícito; prueba de ello es que no se prevé sanción para quien participa en esta práctica. En segundo lugar, en su opinión, la maternidad subrogada no contradice ningún principio moral racionalmente justificado, ni tampoco los principios y valores de la Constitución española, siendo compatible con los tres grandes principios que presiden la bioética: dignidad, no causar daño injustificado, autonomía e igualdad (30).

${ }_{16}$ En cuanto a las alegaciones de parte sobre la discriminación por razón de sexo, en caso de ser denegada la inscripción de filiación en favor de dos varones, son rechazadas por ambos órganos jurisdiccionales, argumentando que la cuestión central no es que se trate de una pareja de hombres o de mujeres quienes reclaman la filiación, sino que el medio empleado para conseguir ser padres está prohibido por la legislación española. Finalmente, en cuanto a la protección del interés superior del menor, se afirma que existen otros instrumentos jurídicos para conseguir la concordancia de la filiación única en los dos países y, en todo caso, tal loable interés no se puede conseguir infringiendo la ley. A este argumento añaden que la prohibición de la gestación por sustitución, al tratar de impedir que los menores puedan ser objeto de comercio, tiene como fin la defensa del interés del menor.

17 Sentencia del Tribunal Supremo № 835/2013.
} 
Convención de Derechos del Niño. Los argumentos esgrimidos se fundamentaron en la discriminación que supondría denegar la filiación por naturaleza a favor de dos varones; la vulneración del interés superior de los menores, si no se les permite ser legalmente hijos de quienes manifestaron su consentimiento para ser padres, frente a la mujer que asumió meramente el papel de parte en un contrato; y el derecho a una identidad única. Finalmente, se apela a que el reconocimiento de la filiación no contradice el orden público internacional español, ya que no se trataría de considerar válido y ejecutar en España un contrato de maternidad subrogada, sino del acceso al Registro Civil español de la filiación resultante del mismo.

Empezando por la última cuestión, el Tribunal Supremo estimó que el control de la certificación registral extranjera no debe limitarse a aspectos meramente formales, sino que ha de extenderse a cuestiones de fondo y, de forma especial, a los derechos fundamentales y principios constitucionales que integran el orden público, actuando como límites al reconocimiento de las decisiones de autoridades extranjeras. Aludiendo a estos derechos y principios, afirmará que no han de admitirse aquellas decisiones que puedan suponer una vulneración de "la dignidad de la mujer gestante y del niño, mercantilizando la gestación y la filiación, cosificando a la mujer gestante y al niño, permitiendo a determinados intermediarios realizar negocio con ellos, posibilitando la explotación del estado de necesidad en que se encuentran mujeres jóvenes en situación de pobreza y creando una especie de ciudadanía censitaria en la que sólo quienes disponen de elevados recursos económicos pueden establecer relaciones paternofiliales vedadas a la mayoría de la población"18. De aquí concluirá el Tribunal Supremo que el artículo 10 de la Ley de técnicas de reproducción humana asistida, referido a la nulidad de los acuerdos de maternidad subrogada, integra el orden público internacional español y, por tanto, "la decisión de la autoridad registral de California al atribuir la condición de padres al matrimonio que contrató la gestación por sustitución con una mujer que dio a luz en dicho Estado es contraria al orden público internacional español al ser incompatible con normas que regulan aspectos esenciales de las relaciones

18 Fundamento Jurídico Tercero, 6 de la Sentencia del Tribunal Supremo 835/2013, de 6 de febrero de 2014. 
familiares, en concreto de la filiación, inspiradas en los valores constitucionales de dignidad de la persona, respeto a su integridad moral y protección de la infancia"19.

Por lo que se refiere a las alegaciones relativas a la posible discriminación, por no permitir la inscripción en el Registro Civil español de la filiación por naturaleza a favor de dos varones, mientras sí es posible inscribir la filiación a favor de dos mujeres, el Tribunal Supremo señala que la desigualdad sustancial entre los supuestos de hecho excluye la existencia de un trato discriminatorio porque la consecuencia legal sea distinta. En todo caso, reitera los argumentos de la sentencia recurrida: la causa de la denegación no es que los solicitantes sean varones, sino que la filiación procede de un acuerdo de maternidad subrogada ${ }^{20}$.

La última cuestión tratada en la Sentencia del Tribunal Supremo fue el interés superior del menor. Para ello, partió de que el interés superior del menor es un concepto 'esencialmente controvertido', que ni permite al juez alcanzar cualquier resultado en aplicación del mismo, ni puede ser satisfecho de un único modo, ni es el único principio que se ha de tomar en consideración, debiendo ser ponderado con otros bienes jurídicos protegidos. Entiende el Tribunal Supremo que la consideración primordial del interés superior del menor ha de utilizarse como criterio para interpretar, aplicar y colmar las lagunas de la ley, pero no para contrariar expresamente lo previsto en la misma. Añade que la determinación de una filiación que contradiga los criterios previstos en la ley supone un perjuicio para el menor y, en este caso, hacerlo a favor de quien realiza un encargo a través de un contrato para su gestación, atenta contra la dignidad del menor y de la gestante, al convertirlos en objetos de tráfico mercantili21 ${ }^{21}$ Con respecto al derecho del menor a una identidad única, no considera el Tribunal que exista riesgo real de vulneración, ya que en el caso enjuiciado los menores no tienen vinculación efectiva con Estados Unidos. Por otro lado, la inmutabilidad o estabilidad de los apellidos es un bien jurídico de menor importancia que los protegidos por la prohibición de la maternidad subrogada ${ }^{22}$.

\footnotetext{
19 Ibidem, Fundamento Jurídico Tercero, 10.

20 Ibidem, Fundamento Jurídico Cuarto, 1 y 2.

${ }^{21}$ Ibidem, Fundamento Jurídico Quinto, 7 y 8.

22 Ibidem, Fundamento Jurídico Quinto, 10.
} 
No obstante, al denegar el reconocimiento de la certificación registral de California, admite el Tribunal Supremo que pueda generarse alguna situación de desprotección para los menores $\mathrm{y}$, en aras a evitar o minimizar sus consecuencias, hará algunas consideraciones. En primer lugar, la denegación de la inscripción afectará exclusivamente a la filiación, no al resto de su contenido, cumpliendo así con el mandato contenido en el artículo 7.1 de la Convención de Derechos del Niño, conforme al cual los niños han de ser inscritos inmediatamente después de su nacimiento y tendrán derecho desde que nacen a un nombre y a una nacionalidad. En segundo lugar, dado que los menores están efectivamente integrados en un núcleo familiar con los recurrentes, se ha de buscar una solución que permita el desarrollo y la protección de los vínculos existentes, instando al Ministerio Fiscal a que ejercite las acciones pertinentes para ello 23 .

En definitiva, la Sentencia del Tribunal Supremo solicita al Ministerio Fiscal que realice las acciones oportunas para determinar la correcta filiación de los menores, en favor de los mismos padres cuya filiación deniega, no impone costas por las "serias dudas de derecho existente" 24 y recuerda que los recurrentes litigan en defensa de la legalidad de una resolución de la Dirección General de los Registros y el Notariado, considerando además relevantes los votos particulares a la sentencia. Votos particulares que insisten en que la filiación ya ha sido determinada por una autoridad extranjera, en cuyo Estado está legalmente permitido el acuerdo del que trae su causa; que el Estado de donde proviene la decisión de filiación es un Estado con el que España comparte ámbitos privilegiados de cooperación jurídica; que estos padres han ejercido su derecho a procrear; que no se puede subestimar la capacidad de consentir de la madre gestante; que el consentimiento de la madre gestante se hace ante una autoridad judicial, que vela porque se trate de una decisión libre; que tratándose de un acuerdo voluntario y libre difícilmente puede tratarse de explotación o cosificación; que el contrato de

\footnotetext{
${ }^{23}$ El Tribunal Supremo apunta alguna solución conforme a la legalidad existente, como la reclamación de la paternidad del padre biológico, si alguno de los recurrentes lo fuera, el acogimiento familiar o la adopción, si puede partirse de la ruptura de todo vínculo de los menores con la mujer que los gestó (Fundamento Jurídico Quinto, 11 y 12). Estas posibilidades abiertas al reconocimiento la filiación de los menores serán las razones principales por las que el Tribunal Supremo deniegue la nulidad de esta Sentencia, solicitada tras el pronunciamiento del Tribunal Europeo de Derechos Humanos en los casos Labassee y Menensson. Cfr. Auto del Tribunal Supremo 02/02/2015.

${ }^{24}$ Fundamento Jurídico Sexto.
} 
maternidad subrogada no puede afectar negativamente al interés superior del menor; finalmente, que de hecho están siendo inscritos niños en los registros civiles, partiendo de circunstancias similares a las de la inscripción cuestionada en la Sentencia ${ }^{25}$.

Además de las inscripciones de las filiaciones en favor de los padres/madres comitentes, procedentes de acuerdos de maternidad subrogada, en sede judicial se han reconocido a esos padres y/o madres el derecho a la prestación por maternidad, por analogía de esta situación a la adopción o acogimiento y la consideración, como "prioritario y fundamental" en tales prestaciones, la atención o cuidado del menor y el estrechamiento de los lazos afectivos, antes que la recuperación de la madre biológica tras el parto ${ }^{26}$.

\section{La necesidad de superar el ámbito del derecho interno: la protección de los derechos del menor}

En este contexto de inscripciones ya realizadas y de derechos reconocidos derivados de las mismas, la Sentencia del Tribunal Supremo no ha venido, ni mucho

\footnotetext{
${ }^{25}$ Sobre esta última consideración se deja constancia de que a partir de la Instrucción de la Dirección General de Registros y Notariado, de 5 de octubre de 2010, se han regularizado y flexibilizado en España las inscripciones de hijos nacidos a través de acuerdos de maternidad subrogada en países cuya normativa lo permite, siempre que alguno de los padres/madres tengan la nacionalidad española. En esta Instrucción se establecen los requisitos que se deben cumplir para acceder al registro civil español, en el caso de los nacimientos de niños en el extranjero cuyas madres gestantes, en virtud de un contrato, han renunciado a la filiación. El objetivo, que se propone la norma, es armonizar la plena protección jurídica del interés superior del menor -facilitando la continuidad transfronteriza de una resolución de filiación ya declarada, evitando que se dote de apariencia de legalidad a supuestos de tráfico internacional de menores y que se vulneren los derechos del menor a conocer su origen biológico-, con otros intereses presentes en estas prácticas y, muy especialmente, el de las mujeres que se prestan a ellas, renunciando a sus derechos como madres. Para hacer efectiva tal inscripción, se precisa una resolución judicial, dictada por tribunal competente, en la que se determine la filiación del nacido, sometida a controles de formalidad y comprobación de que no se hayan vulnerado los derechos del menor y de la madre gestante, en especial en cuanto a su capacidad y la prestación del consentimiento de forma libre y voluntaria. Se analizará también que la resolución sea firme y que los consentimientos prestados sean irrevocables o haya transcurrido, en su caso, el plazo de revocación y que en la documentación conste la identidad de la gestante. Varias han sido las Resoluciones de la Dirección General de Registros y Notariado en aplicación de esta Instrucción: 3 y 6 de mayo 2011, 9 de junio de 2011, 23 de septiembre de 2011, 12 y 22 de diciembre de 2011. Puede verse sobre este asunto Vela Sánchez, A. J., "El interés superior del menor como fundamento de la inscripción de la filiación derivada del convenio de gestación por encargo", Diario La Ley, № 8162, Sección Doctrina, 3 de octubre 2013.

26 Cfr. Sentencia Tribunal Superior de Justicia de Asturias (Sala de lo Social, Sección 11a), núm. 2310/2012, de 20 de septiembre; Sentencia del Tribunal Superior de Justicia de Madrid (Sala de lo Social, Sección 4a), núm. 668/2012, de 18 de octubre; Sentencia Tribunal Superior de Justicia de Cataluña (Sala de lo Social, Sección 1a), núm. 7985/2012, de 23 de noviembre.
} 
menos, a disipar las incertidumbres al respecto 27 . El asunto ha llegado ya al Tribunal Europeo de Derechos Humanos que, en una Sentencia de 26 de junio de 2014, no se limita a realizar una propuesta de cooperación entre los Estados, en atención al interés superior del menor, sino que, partiendo de la vulneración de los derechos del menor, impone obligaciones concretas al Estado. Así procederá a través de una condena a Francia por no reconocer la filiación de menores, nacidos en Estados Unidos mediando contratos de maternidad subrogada, a favor de los padres comitentes. Una Sentencia que, a tenor de lo dispuesto en el artículo 10.2 de la Constitución española, constituye un marco de referencia interpretativa en relación a los derechos fundamentales garantizados en el texto constitucional.

En el caso que da origen a la Sentencia, se trata el asunto del Sr. y la Sra. Menensson y el Sr. y la Sra. Labassee, dos parejas que han tenido a sus hijas en Estados Unidos a través de sendos acuerdos de maternidad subrogada, cuyo reconocimiento de filiación atribuida en aquel país a favor de los ciudadanos franceses les es negada en Francia. Los demandantes alegan ante el Tribunal la vulneración del artículo 8 de la Convención Europea de Derechos Humanos, tanto en relación al derecho a su vida privada y familiar, como al de sus hijas.

El Tribunal Europeo de Derechos Humanos, comienza reconociendo a los Estados un amplio margen de apreciación en la regulación de la gestación por otra persona, habida cuenta de los interrogantes éticos que tal práctica suscita y la ausencia de consenso europeo sobre la cuestión. Sin embargo, tal margen de apreciación se reduce cuando, como este caso, se trata de cuestiones de filiación, ya que afectan a aspectos esenciales de la identidad de las personas. La cuestión se sitúa en el hecho de que negar el reconocimiento de filiación de las menores en favor de los padres comitentes afecta, tanto a las parejas demandantes como a las menores. En tales circunstancias

\footnotetext{
27 Una curiosa situación que no es un caso aislado circunscrito a nuestro país. Prueba de que se trata de un problema que rebasa el ámbito de las fronteras nacionales, es que la Conferencia de Derecho Internacional Privado de la Haya, en marzo de 2012, elaboró un Informe Preliminar sobre los problemas derivados de los acuerdos internacionales de maternidad subrogada. En este Informe se propone la adopción de un instrumento internacional que permita un marco de cooperación entre los distintos Estados -similar al Convenio de la Haya de 29 de mayo de 1993, sobre protección de derechos del niño y cooperación en materia de adopción internacional-, que permita reconocer en países que prohíban la práctica, la filiación de los niños nacidos al amparo de situaciones legales reconocidas en el extranjero, asumiéndose, para ello, un concepto de orden público atenuado por el interés superior del menor. Cfr. http://www.hcch.net/upload/wop/gap2012pd10en.pdf
} 
habrá de determinar si la injerencia de las autoridades francesas en la vida privada y familiar de los implicados es admisible en una sociedad democrática, a la luz del Convenio Europeo de Derechos Humanos. La conclusión será diferente según se trate la incidencia de la medida del gobierno francés en aquellos derechos, al referirse a los padres/madres o a las hijas.

La Corte no estima que se haya producido una violación del derecho a la vida privada y familiar de los padres. Considera que, en ambos casos, ellos y ellas ejercen la paternidad y la maternidad, sin que nada sugiera que exista el riesgo de que sean separados de sus hijas con las que viven, de la forma habitual que lo hace cualquier otra familia. Su peculiar situación legal no les ha impedido el desarrollo de su vida familiar y, por tanto, no han sido afectados en sus derechos amparados por el Convenio Europeo de Derechos Humanos.

La posición del Tribunal es, sin embargo, distinta en relación al derecho a la vida privada de las menores. Respecto a ellas, dirá que la determinación legal de la filiación es imprescindible para poder construir y desarrollar aspectos sustanciales que configuran la propia identidad personal. Una identidad personal que, por otro lado, forma parte del concepto integral de vida privada. En este caso, pese a que las menores son reconocidas como hijas de los Mennensson y los Labassee en otro país, carecen del mismo estatus en el derecho francés, a pesar de que sus padres biológicos son franceses. Tal situación genera una incertidumbre "perturbadora", susceptible de afectar negativamente a la determinación de su identidad en el seno de la sociedad francesa. La falta de reconocimiento legal de la filiación en favor de los ciudadanos franceses, afecta también negativamente a los derechos sucesorios de las menores, privándolas así de otro componente de su identidad.

Ahondando más en el asunto, recuerda el Tribunal que cuando se trata de establecer un equilibrio entre los intereses del Estado y de los individuos, cuando están implicados menores, su interés superior debe prevalecer. Puesto que la decisión de las autoridades francesas ha afectado significativamente a aquel interés superior, concluye que la decisión del Estado francés han sobrepasado los márgenes de apreciación que 
son permisibles, infringiendo el derecho al respeto de la vida privada de las niñas, protegido por el artículo 8 del Convenio Europeo de Derechos Humanos ${ }^{28}$.

Dos aspectos han de ser destacados en esta Sentencia a propósito de la vulneración de los derechos de las niñas a su identidad: uno, la legalidad de los acuerdos de gestación por sustitución en el país donde se llevaron a cabo; el otro, los padres que pretenden el reconocimiento de la filiación lo son biológicamente. No obstante, la ausencia del factor biológico no será un obstáculo para que el Tribunal Europeo de Derechos Humanos considerase la vulneración del artículo 8 del Convenio Europeo de Derechos Humanos, en el caso Paradiso y Campanelli c. Italia, en la Sentencia de 27 de enero de $2015^{29}$. En este caso, el matrimonio Paradiso y Campanelli realizan un contrato de gestación por sustitución en Rusia. Una vez nacido el niño, las autoridades rusas emiten el correspondiente certificado que reconoce al matrimonio contratante como sus padres. Por su parte, las autoridades italianas no sólo deniegan la inscripción en el Registro civil de dicho certificado, sino que tras una prueba de paternidad con resultado negativo, proceden a retirar la custodia del niño a la pareja, ponen en marcha un procedimiento de adopción, abren diligencias penales contra la pareja por alteración de estado civil e infracción de las normas sobre adopción y asignan al niño a una familia de acogida.

El Tribunal Europeo, por una parte, reconoce la legalidad del proceso en Rusia. Por otra parte, en relación a la inexistencia de vínculo biológico entre los recurrentes y el niño, admitirá que se ha producido una vulneración del respeto a la vida familiar, recogido en el artículo 8 del Convenio. Para ello se apoyará en la jurisprudencia reiterada del Tribunal relativa a que la protección del Convenio alcanza a la vida familiar de facto, existan o no vínculos biológicos entre los miembros de la familia. Añadirá el tribunal que la referencia al orden público no puede ser una carta blanca que justifique cualquier medida sin tomar en consideración el interés superior del menor, con independencia de la naturaleza del vínculo genético, o de otro tipo, que una a los miembros de una familia. En este sentido, el alejamiento del menor de su contexto

\footnotetext{
28 CEDH 185/2014, 26.06.2014: Mennenson c. France (requête oㅜ 65192/11) et Labassee c. France (requête no 65941/11). Cfr. http://hudoc.echr.coe.int/sites/eng-press/Pages/search.aspx\#\{"sort":["kpdate Descending"]\}

29 http://hudoc.echr.coe.int/eng?i=001-150770\#\{"itemid":["001-150770"]\}
} 
familiar ha de ser una medida extrema, a la cual sólo se debe recurrir como ultima ratio, justificada en su protección frente a un peligro inmediato.

A juicio del Tribunal, el interés superior del menor ha de valorarse con independencia de la calificación jurídica del hecho de la maternidad subrogada en el país dónde se pretenda el reconocimiento de la filiación del niño. Es más, afirmará que el interés superior del menor debe apreciarse al objeto de evitar que, por el hecho de haber nacido a través de un acuerdo de subrogación, el niño pueda ser privado de su condición de ciudadano o de su identidad. No obstante tales consideraciones, será el mismo interés del menor, cuya vulneración junto al derecho de la vida familiar de los recurrentes constató el Tribunal, el que le permitirá decidir finalmente que el niño no reinicie su vida familiar con los demandantes, ya que el niño está integrado en una familia de acogida y en ella debe permanecer.

Estas Sentencias aumentan aún más las posibilidades de doblegar a una naturaleza y a algunas normas que se resisten a reconocer como padres y madres a quienes tienen una firme voluntad de acceder, ejercer y ser reconocidos como tales. Pero, sobre todo, se pone de manifiesto la dificultad de poner límites a una materia compleja, plagada de valores y derechos, que se entrecruzan e interrogan, en una cultura arraigada, pero en la que se van produciendo cambios sustanciales, no exentos de paradojas y contradicciones.

Se asiste a situaciones novedosas, engarzadas en tradiciones y culturas, cada vez más plurales y cuestionadas, en las que se desafía y rehabilita la maternidad y la paternidad natural, en las que se reestructura la posición jurídica de padres y madres, en las que el cuerpo se fragmenta en partes y se disocia de la mente, en las que ciencia y la tecnología al servicio de la reproducción contribuye a su mercantilización, en las que los óvulos y embriones se convierten materiales "preciosos" y en las que el "útero" parece convertirse en un "espacio público" mientras se reivindica lo privado (31). Del reto de afrontar estas novedades y dificultades depende la protección de algunas familias y, especialmente, de las personas que se encuentran en una situación más vulnerable: mujeres y menores. 


\section{Referencias}

1 Bourdieu, P., Razones prácticas. Sobre la teoría de la acción. Kauf Th. (trad). Barcelona: Anagrama, 2007, p. 133.

2. Rousseau, J. J., Emilio o de la Educación. trad. M. Armiño M (trad) Madrid: Alianza, 1990, p. 491.

3. Butler, J., Deshacer el género. Soley-Beltrán, P. (trad). Barcelona: Paidós, 2008, p. 165

4. Roudinesco, E., La familia en desorden. Molina O. L (trad). Barcelona: Anagrama, 2004, p. 217.

5. Grass, G., Partos mentales o los alemanes se extinguen. Dieterich, G. (trad). Madrid: Alfaguara, 1999.

6 Beck, U. y Beck-Gernsheim, E., El normal caos del amor. Las nuevas formas de relación amorosa. Schmitz, D. (trad) Barcelona: Paidós, 1998, pp. 164.

7 Poisson, J. F., Bioética. ¿El hombre contra el hombre?, Martín M. (trad). Rialp: Alcalá, 2009, p. 147.

8. Alvárez Plaza, C., La búsqueda de la eterna fertilidad. Mercantilismo y altruismo en la donación de semen y óvulos. Jaén: Alcalá, 2008, p. 238.

9. De Lora, P. y Gascón, M., Bioética. Principios, desafíos, debates. Madrid: Alianza, 2008, p. 83.

10. Costa-Lascaux, J., Mujer, procreación, bioética. In Duby, G. y Perrot, M. (eds.), Historia de las mujeres en Occidente. Galmarini,MA (trad). Madrid: Taurus, 1993, pp. 593-594.

11. Ball, P., Contra natura. Sobre la idea de crear seres humanos, trad. Úbeda V. V. (trad). Madrid: Turner, 2012, pp. 245, 285.

12 García Lorca, F., Yerma, edición de I. M. Gil. Madrid: Cátedra, 2012.

13 Goethe, G. Fausto. Salmerón,M (trad). Madrid: Espasa, 2011, pp. 256-257.

14. Barcellona, P., Biopolítica y derechos. , trad. Silveira, H. (trad). In Silveira Gorski, H. C (Ed.), El derecho ante la biotecnología. Estudios sobre la nueva legislación española en biomedicina. Barcelona: Icaria, 2008, p. 48.

15. Quéré, F., La ética y la vida, S. Masó (trad). Madrid: Acento, 1994, p. 135. 
16. Rodotà, S., Aventuras del cuerpo., Silveira H. (trad). In Silveira Gorski, H. C (Ed.), El derecho ante la biotecnología. Estudios sobre la nueva legislación española en biomedicina, 2008, pp. 304-305

17. Pitch, T., Un derecho para dos. La construcción jurídica de género, sexo y sexualidad. García Pascual, C. (trad). Madrid: Trotta, 2003, pp. 67-68.

18. Lozano Estivalis, M., Mujeres autónomas, madres automáticas, Servicio de Publicaciones Universidad de Málaga, 2004, p. 83.

19. Bergel, S. D., Bioética, cuerpo y mercado, Revista Colombiana de Bioética, 2007, 2 (1): 155-157.

20. Sánchez Gómez, Y., El derecho a la reproducción humana. Madrid: Marcial Pons, 1994, pp. 138-142.

21. Fodor, S., ¿Retadas para no ser madres? Lectura crítica de las nuevas tecnologías reproductivas desde el feminismo. In Casado, M. y Royes, A. (coords), Sobre bioética y género. Pamplona: Aranzadi, 2012, p. 264.

22. Elizari Basterra, FJ., Bioética. Madrid: San Pablo, 1994, p. 73.

23. Fábrega Ruiz, CF., Biología y filiación. Aproximación al estudio de las pruebas biológicas de paternidad y de las TRA. Granada: Comares, 1999, p. 115.

24. Charlesworth, M., La bioética en una sociedad liberal. González, M. (trad). Cambridge: University Press, 1996, pp. 109-123.

25. Pateman, C., El contrato sexual, trad. Femenías ML. (trad). Iztapalapa: Anthropos, 1995, p. 295.

26. Shalev, C., Nascere per contratto, Mazzoni y V. Varano C. M. (trad). Milano: Giuffrè, 1992, p. 126.

27. Ferrajoli, L., La cuestión del embrión entre derecho y moral., trad. Ibáñez PA. (trad). In Democracia y garantismo, Madrid,Trotta, 2010, p. 167.

28. Scotti, L. B., El reconocimiento extraterritorial de la maternidad subrogada: una realidad colmada de interrogantes sin respuestas jurídicas. In Pensar en Derecho, n. 1, 2012, pp. 280-282

29. Lamm, E., Gestación por sustitución. Realidad y Derecho. In Dret, Revista para el análisis del derecho, n. 3, 2012, pp. 11-21.

30. Atienza, M., Bioética, Derecho y argumentación. Lima: Palestra, 2010, pp. 150-153. 
Cuadernos Iberomericanos

de Derecho Sanitario

31. Pérez Sedeño, E. y Sánchez, A., Asimetrías y olvidos en las tecnologías de Reproducción Asistida. In Pérez Sedeño E. y Ortega Arjonilla, E. (Eds.), Cartografías del cuerpo. Biopolíticas de la ciencia y la tecnología. Valencia: Cátedra, 2014, p. 239

Recebido em 29/Dez/2015

Aprovado em 02/Mar/2016

Como citar este artigo:

Martínez MOS. Los acuerdos de maternidad subrogada: nuevos retos en la protección de los derechos de la mujer y la infância. Revista Cadernos Ibero-Americanos de Direito Sanitário. 2016 jan./mar, 5(1):146178. 